\title{
A malaria vaccine candidate based on an epitope of the Plasmodium falciparum RH5 protein
}

\author{
Rosalynn L Ord', Jerri C Caldeira², Marilis Rodriguez', Amy Noe ${ }^{3}$, Bryce Chackerian², David S Peabody², \\ Gabriel Gutierrez ${ }^{3}$ and Cheryl A Lobo ${ }^{1 *}$
}

\begin{abstract}
Background: The Plasmodium falciparum protein $\mathrm{RH} 5$ is an adhesin molecule essential for parasite invasion of erythrocytes. Recent studies show that anti-PfRH5 sera have potent invasion-inhibiting activities, supporting the idea that the PfRH5 antigen could form the basis of a vaccine. Therefore, epitopes recognized by neutralizing anti-PfRH5 antibodies could themselves be effective vaccine immunogens if presented in a sufficiently immunogenic fashion. However, the exact regions within PfRH5 that are targets of this invasion-inhibitory activity have yet to be identified.

Methods: A battery of anti-RH5 monoclonal antibodies (mAbs) were produced and screened for their potency by inhibition of invasion assays in vitro. Using an anti-RH5 mAb that completely inhibited invasion as the selecting mAb, affinity-selection using random sequence peptide libraries displayed on virus-like particles of bacteriophage MS2 (MS2 VLPS) was performed. VLPs were sequenced to identify the specific peptide epitopes they encoded and used to raise specific antisera that was in turn tested for inhibition of invasion.

Results: Three anti-RH5 monoclonals $(0.1 \mathrm{mg} / \mathrm{mL})$ were able to inhibit invasion in vitro by $>95 \%$. Affinity-selection with one of these mAbs yielded a VLP which yielded a peptide whose sequence is identical to a portion of PfRH5 itself. The VLP displaying the peptide binds strongly to the antibody, and in immunized animals elicits an anti-PfRH5 antibody response. The resulting antisera against the specific VLP inhibit parasite invasion of erythrocytes more than $90 \%$ in vitro.

Conclusions: Here, data is presented from an anti-PfRH5 mAb that completely inhibits erythrocyte invasion by parasites in vitro, one of the few anti-malarial monoclonal antibodies reported to date that completely inhibits invasion with such potency, adding to other studies that highlight the potential of PfRH5 as a vaccine antigen. The specific neutralization sensitive epitope within $\mathrm{RH} 5$ has been identified, and antibodies against this epitope also elicit high anti-invasion activity, suggesting this epitope could form the basis of an effective vaccine against malaria.
\end{abstract}

\section{Background}

Clinical symptoms of malaria are due to the blood-stage of infection in which merozoites invade erythrocytes, and multiply until the cell bursts, thereby liberating progeny merozoites that in turn invade new erythrocytes [1]. The parasite invades erythrocytes via multiple pathways. In the case of Plasmodium falciparum the two principal routes are the sialic acid (SA)-dependent and SA-independent pathways [2]. The glycophorin (GP) receptors are the main sialylated proteins on the RBC surface, and the parasite adhesins that bind GPs govern the SAdependent pathway. They include members of the

\footnotetext{
* Correspondence: CLobo@nybloodcenter.org

'Department of Blood-Borne Parasites, New York Blood Center, New York, NY 10065, USA

Full list of author information is available at the end of the article
}

erythrocyte binding ligand (EBL) family, such as EBA-175 [1,3-9], and PfRH1 [10]. Antigens identified as utilizing the SA-independent pathway are mainly, but not exclusively, comprised of the reticulocyte binding protein-like homologues (RH), RH2a, RH2b, RH4 and RH5 [9,11-13]. The $\mathrm{RBC}$ receptors bound by $\mathrm{RH} 2 \mathrm{a}$ and $\mathrm{RH} 2 \mathrm{~b}$ have not yet been fully identified; RH4 binds to complement receptor (CR) 1 [14], and RH5 binds to basigin [15].

PfRH5 appears to be essential for erythrocyte invasion. Not only is the PfRH5-basigin interaction required for erythrocyte invasion by all tested strains of $P$. falciparum [15], but repeated unsuccessful attempts to delete the PfRH5 gene suggest the protein is needed for viability $[12,16,17]$. Whole genome sequencing of almost 300 clinical $P$. falciparum isolates identified only five nonsynonymous PfRH5 SNPs [18], revealing that the protein 
has limited sequence polymorphism. Further, our lab and others have shown potent inhibition of invasion using antibodies raised against recombinant PfRH5 protein [19-21]. Recently, naturally acquired anti-PfRH5 antibodies from the sera of malaria patients were also shown to be inhibitory in vitro and correlate with protection from malaria [22,23]. All this points to PfRH5's promise as a vaccine antigen, and to the possibility that epitopes recognized by neutralizing antibodies could themselves be effective vaccine immunogens if presented in a sufficiently immunogenic fashion. However, until recently [24] no study has identified the actual regions on PfRH5 that are either responsible for red cell binding or are targets of this invasion-inhibitory activity.

In this study, a monoclonal antibody that completely prevents red cell invasion by the parasite in vitro was identified, as well as two other mAbs that inhibit invasion by greater than $95 \%$, of any anti-malarial monoclonal antibodies that are able to so potently inhibit parasite invasion. Using a bacteriophage virus-like particle (VLP) based peptide display platform, the specific neutralizationsensitive epitope targeted by one of these monoclonal antibodies was identified. Vaccination with VLPs displaying this epitope elicits antibodies that, in turn, potently inhibit erythrocyte invasion by $P$. falciparum.

\section{Methods}

\section{Animal work and ethics statement}

Animal protocols in this study were reviewed and approved by the A\&G (protocol \#AG-01) and University of New Mexico (protocol \#12-100865-HSC) Institutional Animal Care and Use Committees (IACUC) to ensure they met with strict accordance to the recommendations of the Guide for the Care and Use of Laboratory Animals of the $\mathrm{NIH}$. Isoflurane was used to sedate the mice for immunizations, and all efforts were made to minimize suffering at all times.

\section{Preparation of mouse hybridomas and monoclonal antibodies}

Monoclonal antibodies were generated by Precision Antibody (a wholly owned service division of A\&G Pharmaceutical, Inc.) using their proprietary custom monoclonal antibody development service. SJL/J mice (derived from Swiss Webster) were immunized with recombinant fulllength wheat germ PfRH5 using Precision Antibody's proprietary protocol and adjuvant. Immunogenicity in mice was assessed based on endpoint ELISA using recombinant full-length wheat germ PfRH5 (100 ng/well). Once endpoint titers greater than 1:50,000 were reached, splenocytes from the mouse with the highest titer were harvested for fusion. Hybridomas were single-cell cloned and culture supernatants tested for activity via ELISA using recombinant full-length wheat germ PfRH5 (100 ng/well). Crude supernatants from the highest responders were harvested for testing in invasion inhibition assays. Supernatants which inhibited parasite invasion by $\geq 60 \%$ were selected for monoclonal purification.

\section{Invasion inhibition assay (IIA)}

Parasite culture maintenance and IIAs were performed as described [20]. Purified IgG from naïve mouse sera was used at equivalent concentrations as negative controls in all IIAs. Crude supernatants from mouse hybridoma cultures were tested at 1:5 dilutions. Purified monoclonal antibodies were assayed at 0.025 to $0.1 \mathrm{mg} / \mathrm{mL}$. Cardiac bleed sera from the four animals immunized with the 5A08-VLP were pooled and the IgG fraction was purified using Protein G Sepharose beads, dialyzed overnight in $1 \times$ PBS. Concentrations of IgG were determined against a BSA standard curve on a spectrophotometer (BioRad) and IIAs performed at $0.1 \mathrm{mg} / \mathrm{mL}$ to $1 \mathrm{mg} / \mathrm{mL}$ in $3 \mathrm{D} 7$. All IIAs were done at least 2-3 times, in triplicate.

\section{Immunofluorescence assay (IFA)}

Mature schizont stage 3D7 parasites were smeared onto slides and stored at $-70^{\circ} \mathrm{C}$ before use. Slides were thawed and fixed with $10 \%$ methanol/90\% acetone for $20 \mathrm{~min}$ at room temperature. After air-drying, the smears were coated with anti-PfRH5 monoclonal antibody (1:20 in $1 \times \mathrm{PBS} / 1 \% \mathrm{BSA}$ ) and incubated at room temperature for $1 \mathrm{~h}$. Slides were washed by shaking in $1 \times$ PBS for 5 min then incubated with FITC-conjugated anti-mouse antibody (1:50 in $1 \times \mathrm{PBS} / 1 \% \mathrm{BSA})$ for $1 \mathrm{~h}$ at room temperature protected from light. All slides were washed by shaking in 1x PBS for 5 min then mounted using $10 \mu \mathrm{g} / \mathrm{mL}$ DAPI. Slides were observed under UV light. Supernatants which recognized native PfRH5 antigen by IFA were selected for monoclonal purification. Slides with mature 3D7 parasites were fixed and air dried as before and costained with mouse anti-5A08-VLP ("M $\alpha 5$ A08-VLP"; 1:20) and rabbit anti-PfRhop148 [25] ("R $\alpha$ PfRhop148"; 1:100) or with mouse anti-5A08-VLP ("Mo5A08-VLP"; 1:20) and anti-RhopH3 [25] (RoRhopH3; 1:500) in 1× PBS/1\% BSA. All slides were washed by shaking in $1 \times$ PBS for 5 min then incubated with a mixture of FITC-conjugated anti-mouse antibody (1:50) and TRITC-conjugated anti-rabbit IgG (1:50) in $1 \times \mathrm{PBS} / 1 \% \mathrm{BSA})$ for $1 \mathrm{~h}$ at room temperature protected from light. All slides were washed by shaking in $1 \times$ PBS for $5 \mathrm{~min}$.

\section{Immunoblotting}

Saponin-lysed pellets from mature-stage parasites, was used to make a native protein lysate from mature 3D7 parasites. This was separated on 10\% SDS-PAGE gels by electrophoresis, transferred to nylon membrane. Immunoblotting of the membranes was performed using standard techniques with purified monoclonal antibody at 1:2 
dilution, or polyclonal anti-VLP sera at 1:400 dilution, as the primary antibodies. Mouse anti-HRP at 1:3,000 dilution was used the secondary antibody.

\section{VLP libraries and affinity selection}

Three rounds of affinity-selection were conducted by biopanning using an equal a mixture of four different random sequence peptide libraries constructed by methods described previously [26]. Each library displayed 6mer, $7 \mathrm{mer}$, 8 mer, or 10 mer peptides, was constructed independently, and contained about $10^{10}$ individual members.

\section{A08-VLP immunizations}

The 5A08-VLP selectant was purified as described [27] and three mice were immunized three times by intramuscular injection with $5 \mu \mathrm{g}$ at two-week intervals in the presence of the GLA-SE adjuvant. Two weeks after the last immunization the animals were sacrificed and their sera collected.

\section{ELISA}

The 5A08-VLP selectant was purified by chromatography on Sepharose CL4B [27] and tested for its ability to bind 2E11, 5A08, and 5A03 in direct ELISA. Purified VLPs (500 ng) were adsorbed to a 96-well flat-bottomed ELISA plate (Immulon 2) overnight at $4^{\circ} \mathrm{C}$. Plates were blocked with $5 \%(\mathrm{w} / \mathrm{v}) \mathrm{BSA}$ in PBS for $2 \mathrm{~h}$ at $37^{\circ} \mathrm{C}$ and then washed three times with $1 \mathrm{x}$ PBS. 1uL of sera was diluted in $50 \mu \mathrm{L}$ of PBS containing 2\% BSA was added to the plates and incubated for $1 \mathrm{~h}$ at $37^{\circ} \mathrm{C}$. After three washes with $1 \times \mathrm{PBS}$, an HRP-conjugated goat anti-mouse IgG secondary antibody (Sigma, diluted 1:5,000) was added and incubated for $1 \mathrm{~h}$ at $37^{\circ} \mathrm{C}$. The plates were washed again three times with $1 \mathrm{x}$ PBS, and the colorimetric substrate, 2,2'-azino-bis(3-ethylbenzthiazoline-6sulphonic acid) (ABTS) was added and incubated at room temperature until adequate color development was obtained (about $15 \mathrm{~min}$ ). Absorbance at $405 \mathrm{~nm}$ was measured. All reactions were performed in duplicate. Peptide ELISA was conducted by similar means, but the synthetic peptide SAIKKPVTGGGC (500 ng) was cross-linked through its $\mathrm{C}$-terminal cysteine residue to the amino groups of lysines on streptavidin coated wells using the heterobifunctional cross-linker, succinimidyl 6-[( $\beta$-maleimidopropionamido)hexanoate] (SMPH). After washing, the peptide was reacted with the serial dilutions of sera for $2 \mathrm{~h}$ at room temperature. Reaction with secondary antibody and colorimetric assay were as described above. In this case reactions were conducted in triplicate.

\section{Results and discussion}

\section{Screening hybridoma supernatants}

An ideal malaria vaccine antigen would be highly conserved across a broad spectrum of Plasmodium falciparum strains, and would be essential to parasite viability and reproduction so resistance could not be easily acquired by mutation, or by simply switching off expression. The merozoite protein PfRH5 seems to meet these criteria, especially as several attempts to delete the PfRH5 gene have been unsuccessful, suggesting that PfRH5 is probably essential to parasite viability $[12,16,17]$. To identify epitopes recognized by invasion-inhibiting antibodies, we first identified potent neutralizing monoclonal antibodies by screening 35 hybridoma supernatants from mice immunized with full-length recombinant PfRH5 [20] for the ability to inhibit invasion of erythrocytes by $P$. falciparum strain 3D7 in the invasion inhibition assay (IIA) and to recognize native PfRH5 antigen by immunofluorescence (IFA). Supernatants which showed inhibition $\geq 60 \%$ or were positive by IFA were down selected for purification. Of the eight purified monoclonal antibodies produced, three inhibited 3D7 invasion by $>95 \%$ at $0.1 \mathrm{mg} / \mathrm{ml}$ (mAbs 2E11, 5A03 and 5A08; Figure 1A). The specificity of these three mAbs towards native PfRH5 antigen was confirmed by IFA and immunoblot analysis (Figures 1B and $\mathrm{C}$ ). There have been very few antibodies reported to date that are able to inhibit invasion in vitro by such a degree and this suggests that these mAbs target the neutralizing epitope(s) of RH5.

\section{Affinity selection of a peptide that binds the $5 \mathrm{~A} 08$ antibody}

To identify the epitope targeted specifically by the $5 \mathrm{~A} 08$ $\mathrm{mAb}$, (chosen as it completely inhibited invasion), affinity selection using random sequence peptide libraries displayed on virus-like particles of bacteriophage MS2 (MS2 VLPs) with $5 \mathrm{~A} 08$ as the selecting $\mathrm{mAb}$ (Figure 2) was performed. The method is highly analogous to conventional phage display, but is based on the VLPs that form when MS2 coat protein is expressed from a plasmid in Escherichia coli. The ability to display libraries of diverse peptides on the MS2 VLP and to then affinity select those rare peptides that bind a target antibody depends on two essential conditions: First, it is necessary to identify a surface-exposed site in coat protein that tolerates peptide insertions without disruption of protein folding or VLP assembly. Coat protein's AB-loop is prominently exposed on the VLP surface, but in the wild-type protein AB-loop insertions nearly always interfere with correct folding. Fortunately, a simple means of conferring insertion tolerance was found. Coat protein is a symmetric dimer of identical polypeptide chains with the $\mathrm{N}$-terminus of one monomer lying in close physical proximity to the C-terminus of the other. By duplicating the coat coding sequence and fusing the two copies into a single reading frame, a "single-chain dimer" that is dramatically more stable thermodynamically, and highly tolerant of insertions in one of its two AB-loops was created [27-29]. 

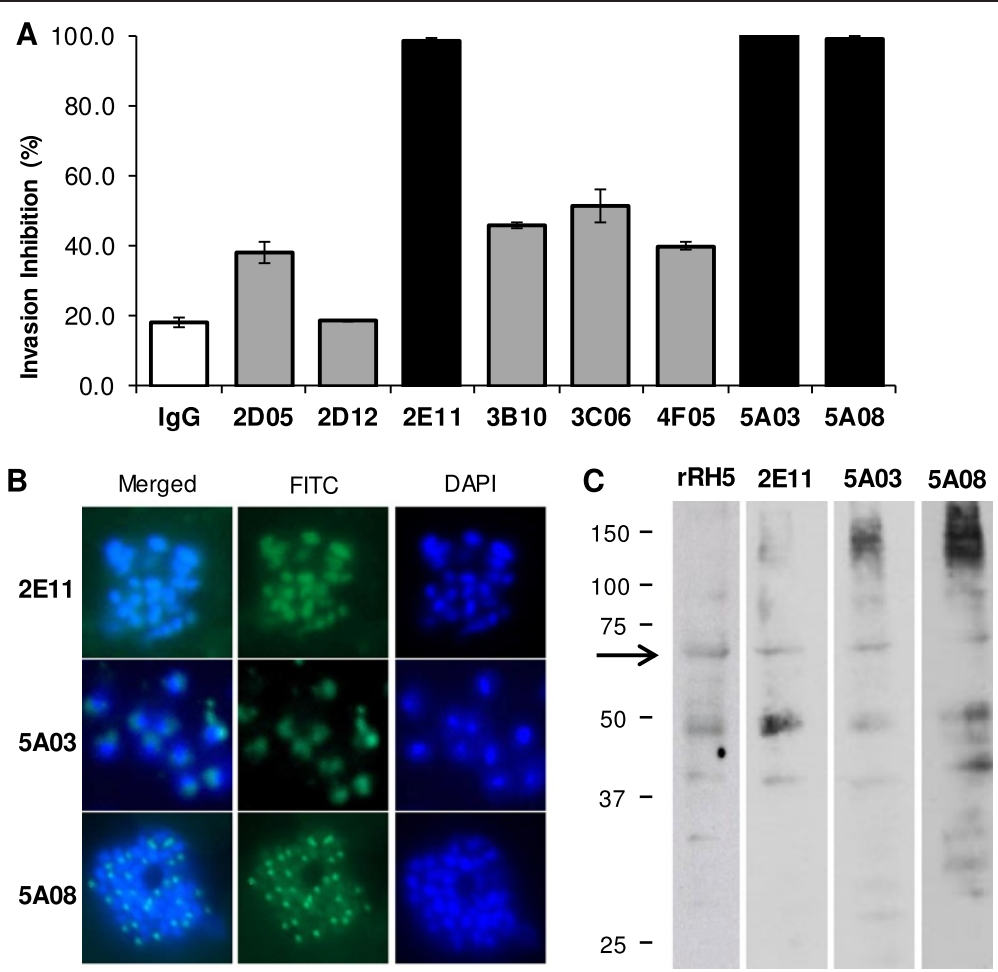

Figure 1 Purified anti-PfRH5 monoclonal antibodies inhibit invasion of $P$. falciparum strain 3D7. (A) The efficacy of purified anti-PfRH5 monoclonal antibodies (mAbs) to prevent invasion of 3D7 parasites was determined at $0.1 \mathrm{mg} / \mathrm{mL}$. Three mAbs, 2E11, 5A03 and 5A08 were able to inhibit invasion by $98 \%, 100 \%$ and $99 \%$, respectively, while the inhibition of the remaining mAbs ranged from $20-45 \%$. Error bars show standard error. (B) Immunofluorescence assays show these three mAbs with high inhibition recognize native PfRH5 located at the apical end of merozoites. (C) Western blot assay on mature 3D7 parasite lysate with these three purified mAbs also shows that native PfRH5 is recognized by each of these antibodies.

Second, to accomplish the linkage of phenotype to genotype that forms the basis of all such technologies, the VLP must encapsidate the nucleic acid that encodes coat protein and its guest peptide. As it happens, the MS2 VLP efficiently encapsidates its own mRNA [27], meaning that affinity selected sequences can be recovered and amplified by reverse transcription and polymerase chain reaction. Because of their multivalent presentation on the VLP surface foreign peptides are highly immunogenic. Therefore, the MS2 VLP can integrate the epitope identification and immunization functions into a single platform and the cloned products of affinity selection can be produced in bacteria, purified and then used directly as vaccines.

The plasmid vectors and methods that facilitate the construction of peptide libraries have been described [26-28]. Random sequences of varying lengths are inserted into one AB-loop of the single-chain dimer. When expressed in bacteria the recombinant coat proteins selfassemble into VLPs, each of which displays a different guest peptide on its surface and encapsidates its own mRNA In the present study, a mixture of random sequence 6-mer, 7-mer, 8-mer and 10-mer libraries, each comprised of about $10^{10}$ independent clones were used [27]. After bio-panning on the 5A08 target, affinity-selected sequences were recovered by reverse transcription of the coat proteinspecific mRNA they contained, followed by polymerase chain reaction. The selected sequences were then re-cloned to produce VLPs for additional rounds of selection. This process normally requires several iterative selection rounds to obtain a relatively simple population of peptides that tightly bind the target antibody.

In this case, however, after only two rounds a virtually homogeneous selectant population was obtained, in which each of twelve individually characterized clones displayed the peptide 8-mer, SAIKKPVT. A third round of affinityselection also identified the SAIKKPVT sequence in 7 of 8 clones, and the very similar 8 -mer TAIKKVPT was identified in one clone. Figure 3A shows the electrophoretic behaviour of the SAIKKPVT-containing particle at the second round of selection compared to unmodified MS2 VLPs. It is unlikely the selection passed through an artificial bottleneck that restricted the diversity of the selected sequence for reasons unrelated to its affinity for the antibody as independent selections gave essentially identical results, but at least one of the sequenced clones shows a slight deviation for the major sequence, replacing the serine at amino acid 1 with threonine. Also, selections 


\section{Affinity Selection of RH5 Mimotope Using RH5-5A08 mAb.}

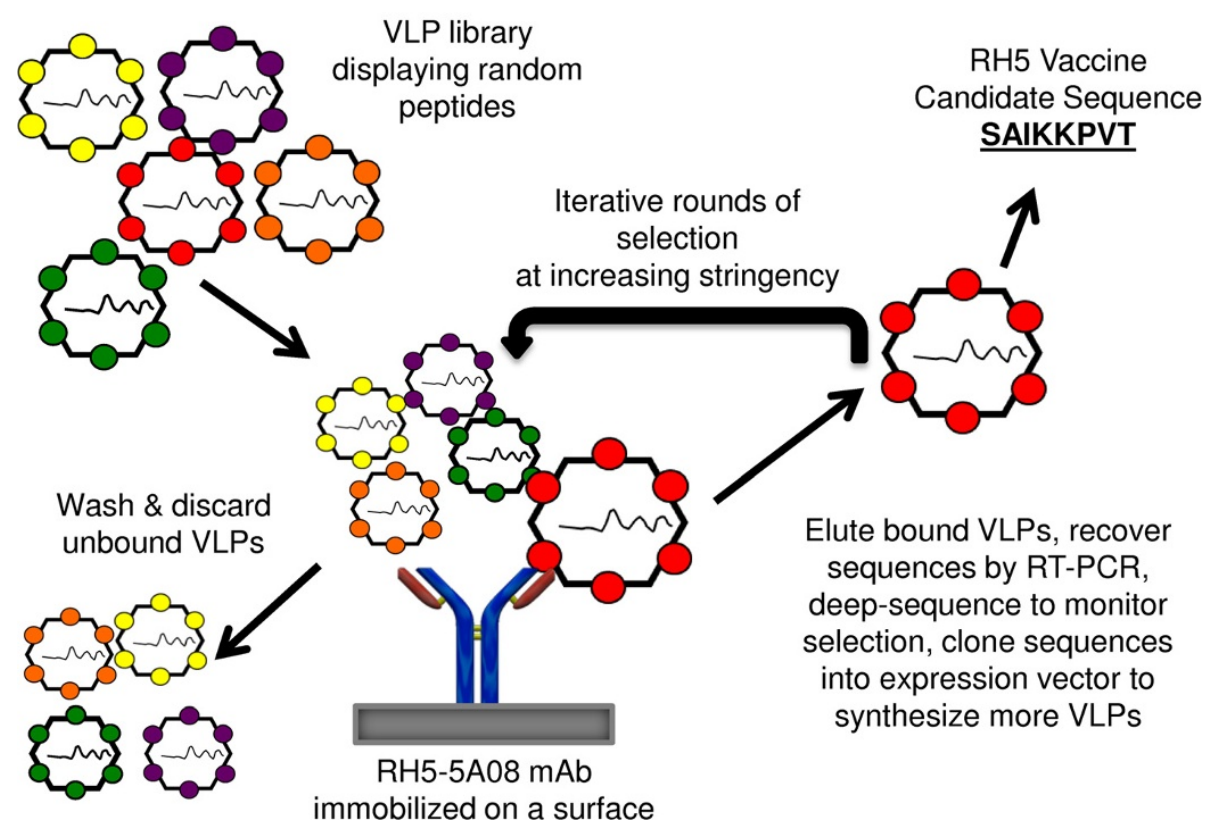

Figure 2 Library construction and affinity selection of MS2 VLPs. When expressed from a plasmid in bacteria, the coat protein of bacteriophage MS2 forms a virus-like particle (VLP), which we have adapted for peptide display and affinity-selection. A complex library of random peptide sequences is constructed at the level of plasmid DNA. When the DNA is expressed in E. coli, a library of corresponding VLPs is produced, as the recombinant coat proteins self-assemble into VLPS, each of which displays a different guest peptide on its surface and encapsidates its own mRNA. These VLPs are subjected to affinity selection with a specific mAb. Unbound VLPs are washed and discarded. VLPs which display a peptide with an affinity for the mAb used are eluted, and subjected to RT-PCR to generate CDNA for another round of affinity selection. After affinity selection, the VLPS were characterized to determine the sequence of the peptide.
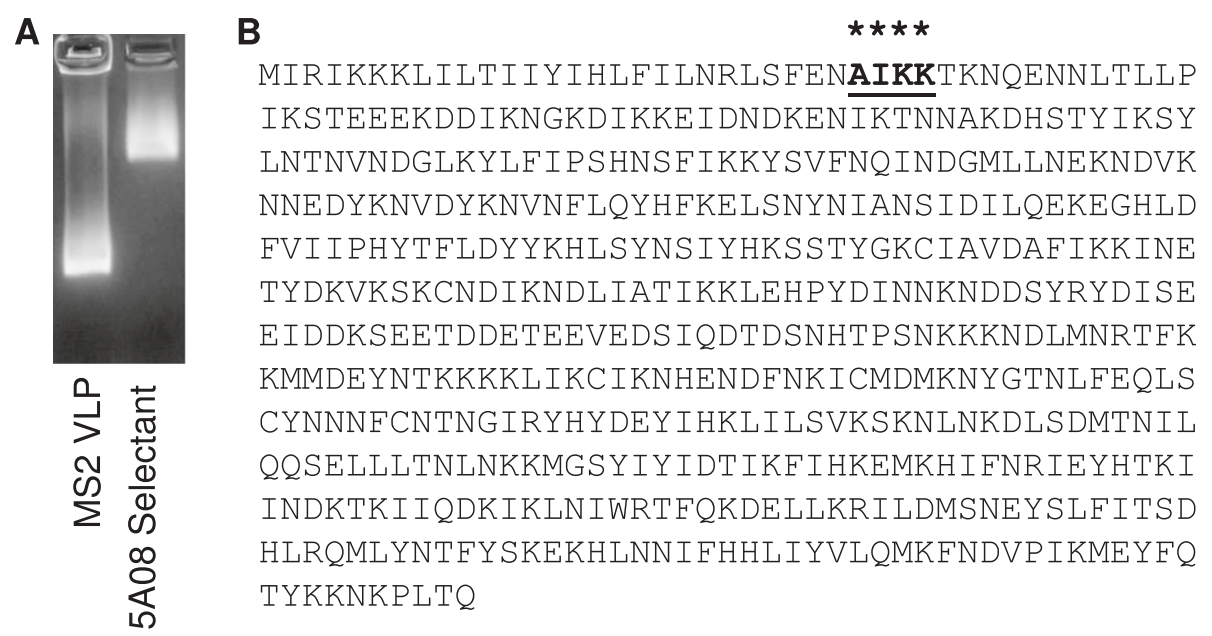

Figure 3 Affinity selection using the anti-PfRH5 mAb 5 A08 identifies a single, short linear epitope, AlKK. (A) Agarose gel of purified, unmodified, MS2 VLP (left lane) and a single clone representative of the highly homogenous selectant population from twelve VLPs selected by the anti-PfRH5-5A08 mAb (right lane), stained with ethidium bromide by virtue of the RNA within each VLP. (B) Characterization by sequencing of clones from each round of affinity-selection showed each RH5-5A08 VLP displayed a four-amino acid sequence at its core, AIKK/R, and that by round two, only VLPs with the AIKK epitope were selected for. The full length PfRH5 sequence (from PlasmoDB, gene ID PF3D7_0424100) contains a 4-amino acid identity to the AIKK sequence that occurs only once near the PfRH5 N-terminus (amino acids 28-31, indicated with asterisks), highlighting the potential importance of this epitope with binding to the RBC receptor during parasite invasion. 
were conducted in parallel on two different anti-HCV mAbs, which effectively serve as positive controls for the selection process as a whole, and at round 3 these anti-HCV selections yielded diverse peptide families, all of which show homology to their known epitopes (data not shown), indicating that the selections functioned normally.

The AIKK sequence contained within the peptide is identical to one encountered near the PfRH5 N-terminus (Figure 3B), suggesting this site represents the 5A08 epitope. It is believed that the $\mathrm{N}$-terminal 21 amino acids of PfRH5 contain a signal sequence that is proteolytically removed from the mature protein $[12,13,17]$. Not only is AIKK the only sequence that survived two selection rounds, but deep sequence analysis of the 200 most abundant first round selectants (from $\sim 2,500$ ) shows that it is only one member of a much larger family sequence family whose common feature is the AIKK (or AIKR) tetrapeptide, and the AIK(K/R) motif always occupies amino acids 2-5 (from the $\mathrm{N}$-end of the sequences characterized. The fact that by round two of affinity-selection SAIKKPVT was so clearly favored over the other members of this family suggests that amino acid residues outside the AIKK identity may serve to most effectively present the core four-amino acid epitope to the antibody in the context of the display site on the MS2 coat protein AB-loop.

Surveys of gene polymorphism by deep sequence analysis of nearly 300 different African malaria samples show the PfRH5 protein sequence is highly conserved $[18,30]$ and that none of the known polymorphisms affects the AIKK epitope. The specific role of the AIKK epitope in PfRH5 function is not known, but it is tempting to think the epitope participates directly in interactions with the
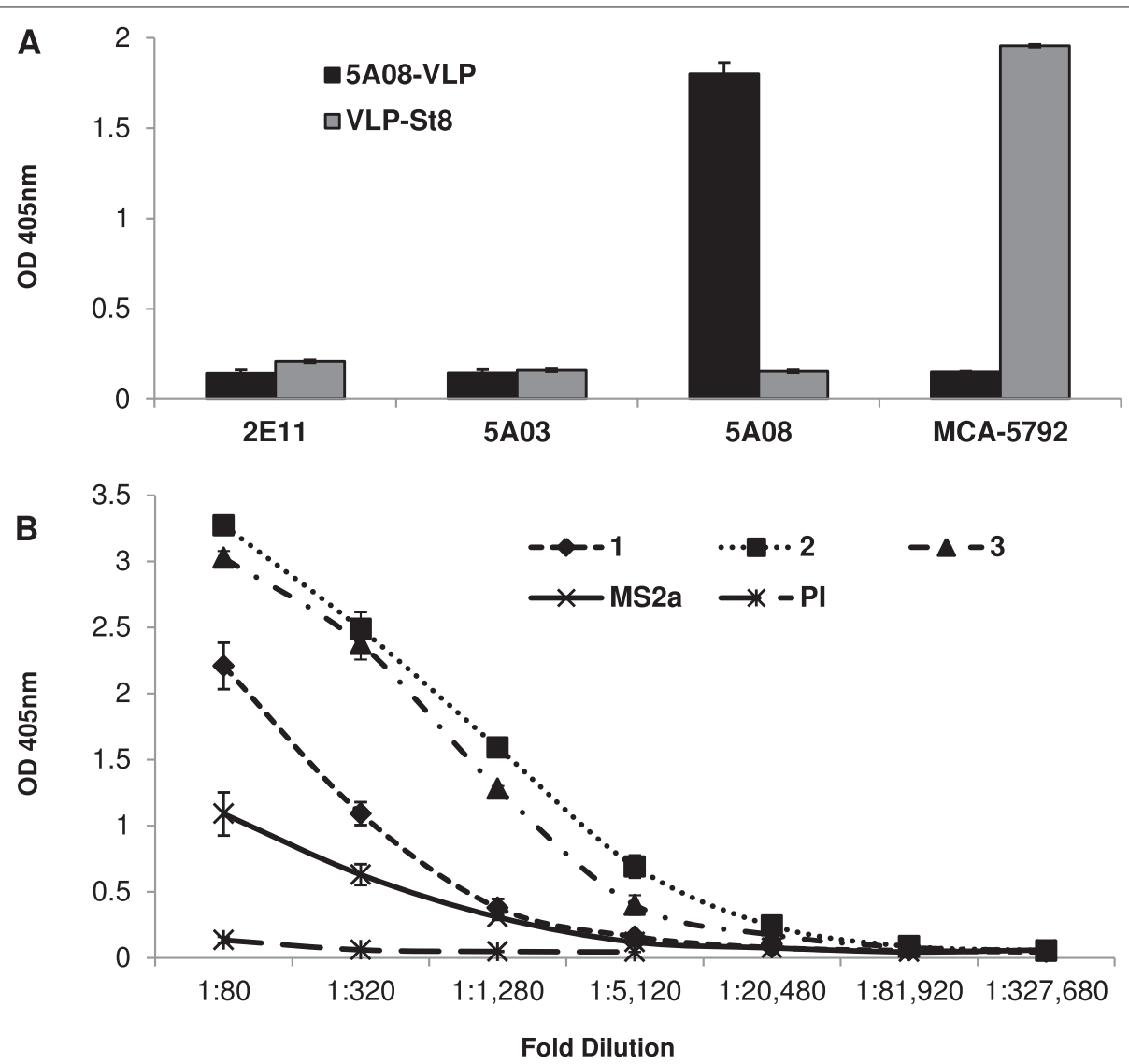

Figure 4 The anti-PfRH5 mAb 5 A08 specifically recognizes the affinity-selected VLP. (A) ELISA performed with different mAbs against with the 5A08-VLP, and a MCA-5792-VLP, show that the 5A08-VLP reacts with the anti-PfRH5 5 A08 mAb, but not with the two other anti-PfRH5 mAbs, 2E11 and 5A03, nor with MCA-5792 used here as a control, which reacts well with its own selectant. MCA-5792 recognizes Staphylococcus aureus peptidoglycan; St8 is a VLP affinity-selected for its ability to interact with MCA-5792. (B) The 5A08-selected VLP elicits antibodies that recognize the synthetic SAIKKPVTGGGC peptide. ELISA assay shows the anti-peptide antibody titers of sera from mice immunized with the synthetic VLP bearing the SAIKKPVTGGGC peptide. The synthetic peptide was bound to the plates by chemical cross-linking. Pooled pre-immune sera from the immunized mice show negligible anti-VLP peptide antibody titers in naïve animals. Pooled sera from mice immunized with MS2 itself also showed some reaction with the peptide, but it was much lower and decreased quickly with dilution. However, sera from all three mice immunized (indicated as 1,2 and 3) showed high anti-VLP peptide antibody titers, two of the three giving signals well above background levels beyond the 1:5,120 dilution point. 
basigin receptor on erythrocytes, and that the presence of the 5A08 monoclonal antibody directly interferes with binding. A recent report described neutralizing mAbs that bind epitopes found in at least two defined regions of the PfRH5 primary sequence [24]. Neither overlaps the predicted 5A08 epitope. Interestingly the same report found two classes of mAbs that had a severe inhibitory effect on parasite invasion, yet only one group inhibited PfRH5-Basigin binding [24].

\section{Immunization with the 5A08 VLP selectant elicits} antibodies that recognize PfRH5 and strongly inhibit parasite entry into erythrocytes

The purified 5A08 VLP selectant was tested by direct ELISA for its ability to bind each of the three invasioninhibiting anti-PfRH5 mAbs (i.e. 5A08, 5A03, and 2E11). As expected of an affinity-selectant, it bound significantly only to the 5A08 antibody (Figure 4A). Three mice were immunized with the VLP displaying the SAIKKPVT sequence by intramuscular injection with $5 \mu \mathrm{g}$ of VLP, 3 times at two-week intervals. To assess the relative anti-peptide titers of the antisera, a synthetic peptide representing the selected sequence was synthesized and tested in ELISA for its ability to bind sera from the immunized animals using sera serially diluted from 1:80 to $1: 81,920$ (Figure $4 \mathrm{~B}$ ). Unsurprisingly, the 5A08-VLPs elicit antibodies that recognize a synthetic version of the immunizing peptide. Most importantly, purified IgG from the anti-5A08-VLP antiserum was potently inhibitory in GIA, showing greater than $90 \%$ inhibition of parasite entry at a concentration of $1 \mathrm{mg} / \mathrm{mL}$ IgG concentration (Figure 5A). Remembering that only a small fraction of the total IgG is likely to be specific for the 5A08 epitope, this level of inhibition promises a significantly improved route for eliciting anti-invasion antibodies. The reaction of the antisera with native PfRH5 was confirmed by Western blot analysis (Figure 5B), where it can be seen that sera against 5A08-VLP (lane 2) reacts with the same polypeptides as seen by antibodies to the full-length RH5 (lane 1). Immunoblot analysis with negative control sera directed against empty VLPs did not react with the $63 \mathrm{kDa}$ PfRH5 band (lane 3). IFA analysis was also performed to confirm rhoptry localization of the target of the 5A08-VLP sera (Figure 5C). Co-staining using anti-5A08-VLP sera along with antibodies to known rhoptry markers, PfRhop148 (Figure 5C, top panel) and RhopH3 (Figure 5C, bottom

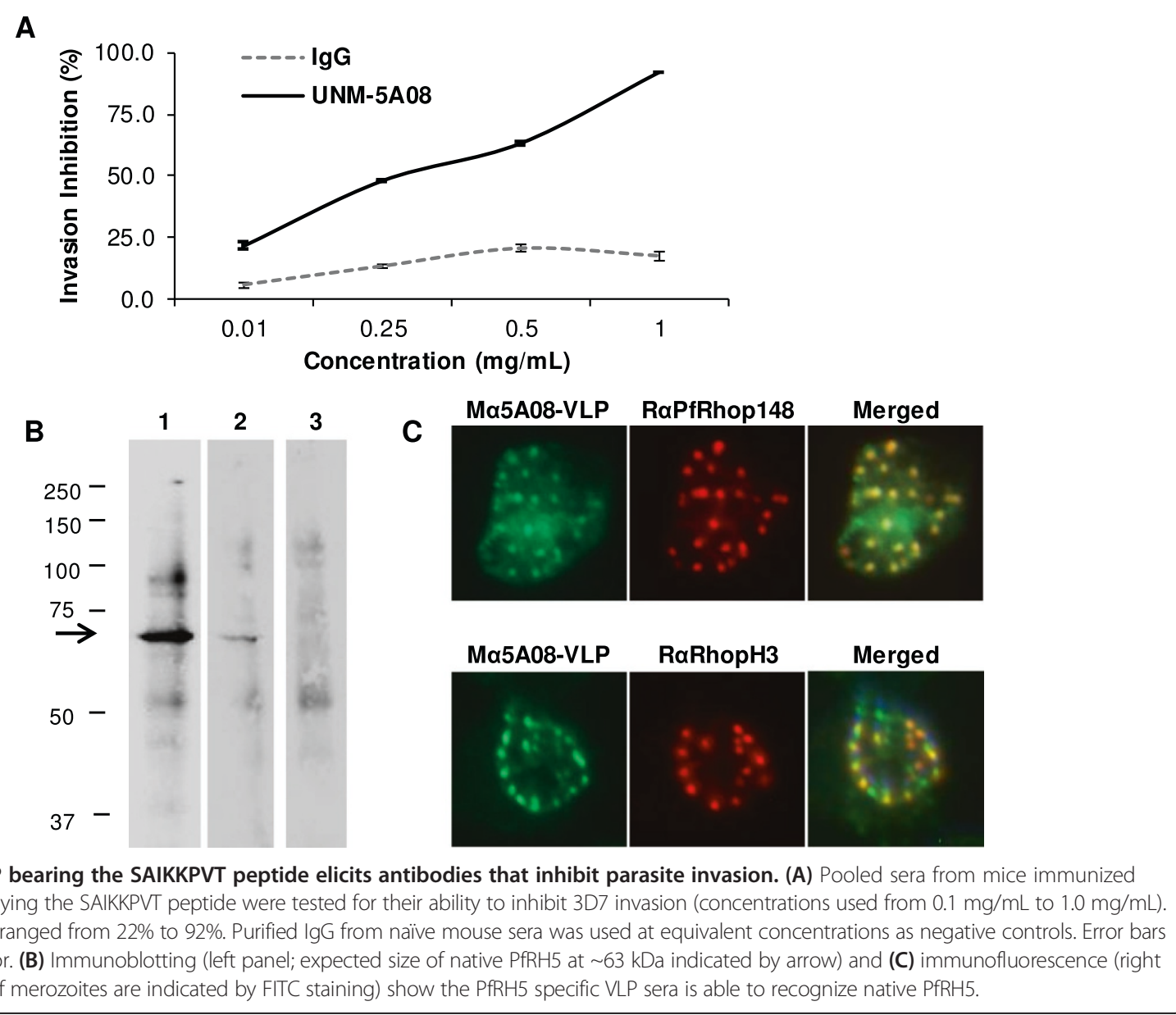


panel) showed specific rhoptry localization of the target of the 5A08-VLP. These studies thus indicated that the 5A08-VLP recognizes native PfRH5 in the rhoptries.

Several groups have shown that the intact PfRH5 protein, whether administered as a recombinant protein or expressed from viral vectors, elicits antibodies that inhibit parasite entry into erythrocytes in vitro $[18,19,21]$. But subunit vaccines generally elicit strong responses only after several administrations, and the immunity they engender is frequently relatively short-lived [31]. This is probably because the survival potential of a plasma cell and its level of antibody production are determined during its initial interaction with antigen. Recombinant proteins, and other antigens that lack multivalency, do not strongly activate $\mathrm{B}$ cell activation through BCR crosslinking $[32,33]$. Because of their multivalency, on the other hand, VLPs present peptide epitopes as potent immunogens that elicit strong and durable antibody responses, often after only a single administration [34]. In addition to its high immunogenicity, the MS2 VLP has the ability to identify epitopes by affinity-selection. Given a mAb with neutralizing activity, the work presented here shows that the MS2 VLP can provide a direct route to an epitope-specific vaccine candidate.

\section{Conclusions}

These results add to other studies that point to the potential of PfRH5 as a vaccine antigen [18-24,35], although none of the antibodies reported so far has approached the high level of invasion inhibition shown by our three mAbs, 2E11, 5A03 and 5A08, or the sera that were raised against the VLP that displays the 5A08 epitope. This highlights the relative importance of the AIKK epitope for effective parasite neutralization. Further, the work presented here shows that when displayed on the MS2 VLP even a single PfRH5 epitope can elicit antibodies that potently inhibit erythrocyte invasion by parasites. The high immunogenicity of peptides displayed multivalently on MS2 VLPs permits the use of the affinity-selected VLP itself as a vaccine immunogen. Thus the VLP integrates the epitope discovery and immunization functions into a single platform. While the PfRH5 protein itself might form the basis of an effective subunit vaccine, an epitopespecific vaccine based on the MS2 VLP platform has some advantages. Clinical trials conducted with VLP-based biologics have demonstrated that these products have good safety profiles [36-39]. Even at low doses VLPs elicit hightiter and remarkably durable antibody responses, potentially obviating the need for adjuvants [40]. Furthermore, because MS2 VLPs are produced at high levels in bacteria they should be relatively easy and cheap to manufacture, and the particle itself is relatively stable. These features are particularly important in the developing world, where the burden of malaria is the highest.

\section{Competing interests}

The authors declare that they have no competing interests.

\section{Authors' contributions}

RLO participated in the study design, performed the IFA and IIA, conducted the sequence alignment, and wrote the paper. JC performed the bio-panning studies and the ELISAs. MR performed the Western Blots and IFA. AN participated in design of study and data analysis. BC participated in VLP technology, VLP immunizations, data analysis and study design. DP pioneered the VLP technique, participated in study design, data analysis and co-wrote the paper. GG participated in the study design and data analysis. CAL participated in the study design, analyzed the results and co-wrote the paper. All authors read and approved the final manuscript.

\section{Acknowledgments}

This work was funded by NIAID/DMID contract Al-N01-045210 to Leidos. We are indebted to Dr. Annie Mo for the many valuable discussions during the course of this project.

\section{Author details}

'Department of Blood-Borne Parasites, New York Blood Center, New York, NY 10065, USA. ²Department of Molecular Genetics and Microbiology, University of New Mexico School of Medicine, Albuquerque, New Mexico, USA. ${ }^{3}$ Leidos, Inc., Reston, Viginia, USA.

Received: 10 April 2014 Accepted: 8 August 2014

Published: 18 August 2014

\section{References}

1. Miller LH, Baruch DI, Marsh K, Doumbo OK: The pathogenic basis of malaria. Nature 2002, 415:673-679.

2. Hadley TJ, Klotz FW, Pasvol G, Haynes JD, McGinniss MH, Okubo Y, Miller LH: Falciparum malaria parasites invade erythrocytes that lack glycophorin A and $B$ (MkMk). Strain differences indicate receptor heterogeneity and two pathways for invasion. J Clin Invest 1987, 80:1190-1193.

3. Camus D, Hadley TJ: A Plasmodium falciparum antigen that binds to host erythrocytes and merozoites. Science 1985, 230:553-556.

4. Dolan SA, Proctor $\mathrm{L}$, Alling DW, Okubo Y, Wellems TE, Miller LH: Glycophorin B as an EBA-175 independent Plasmodium falciparum receptor of human erythrocytes. Mol Biochem Parasitol 1994, 64:55-63.

5. Sim BK, Chitnis CE, Wasniowska K, Hadley TJ, Miller LH: Receptor and ligand domains for invasion of erythrocytes by Plasmodium falciparum. Science 1994, 264:1941-1944.

6. Peterson DS, Wellems TE: EBL-1, a putative erythrocyte binding protein of Plasmodium falciparum, maps within a favored linkage group in two genetic crosses. Mol Biochem Parasitol 2000, 105:105-113.

7. Adams JH, Blair PL, Kaneko O, Peterson DS: An expanding ebl family of Plasmodium falciparum. Trends Parasitol 2001, 17:297-299.

8. Mayer DC, Mu JB, Kaneko O, Duan J, Su XZ, Miller LH: Polymorphism in the Plasmodium falciparum erythrocyte-binding ligand JESEBL/EBA-181 alters its receptor specificity. Proc Natl Acad Sci U S A 2004, 101:2518-2523.

9. Gaur D, Singh S, Singh S, Jiang L, Diouf A, Miller LH: Recombinant Plasmodium falciparum reticulocyte homology protein 4 binds to erythrocytes and blocks invasion. Proc Natl Acad Sci U S A 2007, 104:17789-17794.

10. Triglia T, Duraisingh MT, Good RT, Cowman AF: Reticulocyte-binding protein homologue 1 is required for sialic acid-dependent invasion into human erythrocytes by Plasmodium falciparum. Mol Microbiol 2005, 55:162-174.

11. Duraisingh MT, Maier AG, Triglia T, Cowman AF: Erythrocyte-binding antigen 175 mediates invasion in Plasmodium falciparum utilizing sialic acid-dependent and -independent pathways. Proc Natl Acad Sci U S A 2003, 100:4796-4801.

12. Hayton K, Gaur D, Liu A, Takahashi J, Henschen B, Singh S, Lambert L, Furuya T, Bouttenot R, Doll M, Nawaz F, Mu J, Jiang L, Miller LH, Wellems TE: Erythrocyte binding protein $\mathrm{PfRH} 5$ polymorphisms determine speciesspecific pathways of Plasmodium falciparum invasion. Cell Host Microbe 2008, 4:40-51.

13. Rodriguez M, Lustigman S, Montero E, Oksov Y, Lobo CA: PfRH5: a novel reticulocyte-binding family homolog of Plasmodium falciparum that binds to the erythrocyte, and an investigation of its receptor. PLOS One 2008, 3:e3300 
14. Tham WH, Wilson DW, Lopaticki S, Schmidt CQ, Tetteh-Quarcoo PB, Barlow PN, Richard D, Corbin JE, Beeson JG, Cowman AF: Complement receptor 1 is the host erythrocyte receptor for Plasmodium falciparum PfRh4 invasion ligand. Proc Natl Acad Sci U S A 2010, 107:17327-17332.

15. Crosnier C, Bustamante LY, Bartholdson SJ, Bei AK, Theron M, Uchikawa M, Mboup S, Ndir O, Kwiatkowski DP, Duraisingh MT, Rayner JC, Wright GJ: Basigin is a receptor essential for erythrocyte invasion by Plasmodium falciparum. Nature 2011, 480:534-537.

16. Cowman AF, Crabb BS: Invasion of red blood cells by malaria parasites. Cell 2006, 124:755-766.

17. Baum J, Chen L, Healer J, Lopaticki S, Boyle M, Triglia T, Ehlgen F, Ralph SA Beeson JG, Cowman AF: Reticulocyte-binding protein homologue 5 - an essential adhesin involved in invasion of human erythrocytes by Plasmodium falciparum. Int J Parasitol 2009, 39:371-380.

18. Bustamante LY, Bartholdson SJ, Crosnier C, Campos MG, Wanaguru M, Nguon C, Kwiatkowski DP, Wright GJ, Rayner JC: A full-length recombinant Plasmodium falciparum PfRH5 protein induces inhibitory antibodies that are effective across common PfRH5 genetic variants. Vaccine 2013, 31:373-379.

19. Douglas AD, Williams AR, Illingworth JJ, Kamuyu G, Biswas S, Goodman AL, Wyllie DH, Crosnier C, Miura K, Wright GJ, Long CA, Osier FH, Marsh K, Turner AV, Hill AV, Draper SJ: The blood-stage malaria antigen PfRH5 is susceptible to vaccine-inducible cross-strain neutralizing antibody. Nat Commun 2011, 2:601.

20. Ord RL, Rodriguez M, Yamasaki T, Takeo S, Tsuboi T, Lobo CA: Targeting sialic acid dependent and independent pathways of invasion in Plasmodium falciparum. PLoS One 2012, 7:e30251.

21. Reddy KS, Pandey AK, Singh H, Sahar T, Emmanuel A, Chitnis CE, Chauhan VS, Gaur D: Bacterially expressed full-length recombinant Plasmodium falciparum RH5 protein binds erythrocytes and elicits potent strain-transcending parasite-neutralizing antibodies. Infect Immun 2014, 82:152-164.

22. Patel SD, Ahouidi AD, Bei AK, Dieye TN, Mboup S, Harrison SC, Duraisingh MT: Plasmodium falciparum merozoite surface antigen, $\mathrm{PfRH} 5$, elicits detectable levels of invasion-inhibiting antibodies in humans. J Infect Dis 2013, 208:1679-1687.

23. Tran TM, Ongoiba A, Coursen J, Crosnier C, Diouf A, Huang CY, Li S, Doumbo S, Doumtabe D, Kone Y, Bathily A, Dia S, Niangaly M, Dara C, Sangala J, Miller LH, Doumbo OK, Kayentao K, Long CA, Miura K, Wright GJ, Traore B, Crompton PD: Naturally acquired antibodies specific for Plasmodium falciparum reticulocyte-binding protein homologue 5 inhibit parasite growth and predict protection from malaria. J Infect Dis 2014, 209:789-798.

24. Douglas AD, Williams AR, Knuepfer E, Illingworth JJ, Furze JM, Crosnier C, Choudhary P, Bustamante LY, Zakutansky SE, Awuah DK, Alanine DG, Theron M, Worth A, Shimkets R, Rayner JC, Holder AA, Wright GJ, Draper SJ: Neutralization of Plasmodium falciparum merozoites by antibodies against PfRH5. J Immunol 2014, 192:245-258.

25. Lobo CA, Rodriguez M, Hou G, Perkins M, Oskov Y, Lustigman S: Characterization of PfRhop148, a novel rhoptry protein of Plasmodium falciparum. Mol Biochem Parasitol 2003, 128:59-65.

26. Chackerian B, Caldeira Jdo C, Peabody J, Peabody DS: Peptide epitope identification by affinity selection on bacteriophage MS2 virus-like particles. J Mol Biol 2011, 409:225-237.

27. Peabody DS, Manifold-Wheeler B, Medford A, Jordan SK, do Carmo Caldeira J, Chackerian B: Immunogenic display of diverse peptides on virus-like particles of RNA phage MS2. J Mol Biol 2008, 380:252-263.

28. Caldeira Jdo C, Medford A, Kines RC, Lino CA, Schiller JT, Chackerian B, Peabody DS: Immunogenic display of diverse peptides, including a broadly cross-type neutralizing human papillomavirus L2 epitope, on virus-like particles of the RNA bacteriophage PP7. Vaccine 2010, 28:4384-4393.

29. Peabody DS: Subunit fusion confers tolerance to peptide insertions in a virus coat protein. Arch Biochem Biophys 1997, 347:85-92.

30. Hayton K, Dumoulin P, Henschen B, Liu A, Papakrivos J, Wellems TE: Various PfRH5 polymorphisms can support Plasmodium falciparum invasion into the erythrocytes of owl monkeys and rats. Mol Biochem Parasitol 2013, 187:103-110.

31. Amanna IJ, Slifka MK: Mechanisms that determine plasma cell lifespan and the duration of humoral immunity. Immunol Rev 2010, 236:125-138.

32. Paus D, Phan TG, Chan TD, Gardam S, Basten A, Brink R: Antigen recognition strength regulates the choice between extrafollicular plasma cell and germinal center B cell differentiation. J Exp Med 2006, 203:1081-1091.
33. Pierce SK, Liu W: The tipping points in the initiation of $B$ cell signalling: how small changes make big differences. Nat Rev Immunol 2010, 10:767-777.

34. Safaeian M, Porras C, Pan Y, Kreimer A, Schiller JT, Gonzalez P, Lowy DR, Wacholder S, Schiffman M, Rodriguez AC, Herrero R, Kemp T, Shelton G, Quint W, van Doorn L, Hildesheim A, Pinto LA: Durable antibody responses following one dose of the bivalent human papillomavirus L1 virus-like particle vaccine in the Costa Rica Vaccine Trial. Cancer Prev Res (Phila) 2013, 6:1242-1250.

35. Williams AR, Douglas AD, Miura K, Illingworth JJ, Choudhary P, Murungi LM, Furze JM, Diouf A, Miotto O, Crosnier C, Wright GJ, Kwiatkowski DP, Fairhurst RM, Long CA, Draper SJ: Enhancing blockade of Plasmodium falciparum erythrocyte invasion: assessing combinations of antibodies against PfRH5 and other merozoite antigens. PLoS Pathog 2012, 8:e1002991.

36. Hillman RJ, Giuliano AR, Palefsky JM, Goldstone S, Moreira ED Jr, Vardas E, Aranda C, Jessen H, Ferris DG, Coutlee F, Marshall JB, Vuocolo S, Haupt RM Guris D, Garner El: Immunogenicity of the quadrivalent human papillomavirus (type 6/11/16/18) vaccine in males 16 to 26 years old. Clin Vaccine Immunol 2012, 19:261-267.

37. Lopez-Macias C: Virus-like particle (VLP)-based vaccines for pandemic influenza: performance of a VLP vaccine during the 2009 influenza pandemic. Hum Vaccin Immunother 2012, 8:411-414.

38. Wang JW, Roden RB: Virus-like particles for the prevention of human papillomavirus-associated malignancies. Expert Rev Vaccines 2013, 12:129-141.

39. Wu T, Li SW, Zhang J, Ng MH, Xia NS, Zhao Q: Hepatitis E vaccine development: a 14 year odyssey. Hum Vaccin Immunother 2012, 8:823-827.

40. Tumban E, Peabody J, Peabody DS, Chackerian B: A universal virus-like particle-based vaccine for human papillomavirus: longevity of protection and role of endogenous and exogenous adjuvants. Vaccine 2013, 31:4647-4654

doi:10.1186/1475-2875-13-326

Cite this article as: Ord et al:: A malaria vaccine candidate based on an epitope of the Plasmodium falciparum RH5 protein. Malaria Journal 2014 13:326

\section{Submit your next manuscript to BioMed Central and take full advantage of:}

- Convenient online submission

- Thorough peer review

- No space constraints or color figure charges

- Immediate publication on acceptance

- Inclusion in PubMed, CAS, Scopus and Google Scholar

- Research which is freely available for redistribution
C) Biomed Central 